\title{
ANALISIS TINGKAT KEPUASAN PASIEN TERHADAP MUTU PELAYANAN RUMAH SAKIT BERDASARKAN METODE SERVICE QUALITY (SERVQUAL)
}

\author{
BENY IRAWAN ${ }^{1}$, ERWIN DANIEL SITANGGANG ${ }^{2}$ \\ ${ }^{1}$ INSTITUT KESEHATAN MEDISTRA LUBUK PAKAM \\ 2 AMIK Medan Business Polytechnic \\ Jl. Sudirman No.38 Lubuk Pakam Kab. Deli Serdang \\ e-mail :benyirawan77@gmail.com \\ DOI : $10.35451 /$ jkf.v3i1.522
}

\begin{abstract}
Measuring the level of patient satisfaction at the hospital is done to measure the performance of the services provided. In measuring the level of satisfaction in the March 2020 period at the Grandmed hospital, it involved 98 inpatients as a sample of a population of 129 patients. The data collection techniques were used non-probability sampling with purposive random sampling and purposive random sampling. By using the servqual method, as a whole, it was by the expectation with a satisfaction level gap score of 0.10 with a patient satisfaction level of $53.06 \%$. In the dimension of the gap score was 0.22 for the Assurance variable, 0.16 for the Physical Evidence variable, 0.12 for the Empathy variable, 0.08 for the Reliability variable, and -0.08 for the Responsiveness variable. To improve service quality, it is necessary to improve the performance of the attributes of the statement, especially those in the reliability dimension.
\end{abstract}

Keywords: Service, level of satisfaction, servqual, hospital, patient

\section{PENDAhUlUAN}

Pelayanan merupakan bentuk tindakan yang ditujukan kepada pelanggan baik berupa materi maupun non materi dengan tujuan memenuhi kebutuhan pelanggan secara langsung agar dapat menyelesaikan masalah pelanggan. Pelayanan dapat ditemui dalam kehidupan sehari-hari, salah satunya didapatkan di rumah sakit. Rumah sakit merupakan salah satu penyedia layanan yang bergerak dibidang kesehatan dan selanjutnya yang menerima pelayanan atau pelanggan disebut dengan pasien. Sebagai penerima layanan kesehatan, pasien harusnya mendapatkan pelayanan yang terbaik sesuai dengan harapan mereka akan kenyataan pelayanan yang diberikan oleh rumah sakit. Tetapi harapan dari setiap pasien tidak sama sehingga tingkat kepuasan dari pasien pasti akan berbeda-beda. Untuk mendapatkan tingkat kepuasan dari pasien, rumah sakit haruslah mengukur tingkat kepuasan agar dapat meningkatkan pelayanan yang mereka berikan dikemudian hari.

Dalam mengukur pelayanan yang diberikan, penyebaran kuesioner merupakan salah satu instrumen untuk mengukur kenyataan dari pelayanan yang diharapkan. Hasil kuesioner tersebut diolah menggunakan sebuah metode untuk mendapatkan informasi berupa tingkat kepuasan pasien. Hasil dari analisis metode tersebut akan 
Received: 13 Oktober 2020 :: Accepted: 14 Oktober 2020 :: Published: 31 Oktober 2020

menjadi acuan dari penyedia layanan dalam meningkatkan kualitas pelayanan.

Metode yang digunakan untuk mengukur tingkat kepuasan pasien oleh penulis dalam penelitian ini adalah Service Quality (Servqual). Metode ini pertama kali dikenalkan oleh Parasuraman, Zeithaml, dan Berry dalam Lissa (2016), yang telah diuji secara empiris dan telah dikembangkan kedalam instrument pengukuran untuk perspektif mutu menurut pelanggan yang meliputi lima dimensi, yaitu: Tangible, Reliability, Responsiveness, Assurance dan Empathy (Kamil, 2017). Instrument dalam metode ini telah berkembang menjadi standar untuk penilaian atas berbagai dimensi kualitas pelayanan. Dengan menggunakan metode ini, akan didapatkan nilai gap (kesenjangan) dari setiap atributatribut dimensinya, akan diketahui atribut-atribut yang harus mengalami perbaikan, serta akan didapatkan kesenjangan antara harapan dan kenyataan yang didapatkan dari pelayanan.

\section{TINJAUAN PUSTAKA}

Penelitianterdahulu yang berkenaan dengan pengukuran tingkat kepuasanakan pelayanan yang diharapkan oleh pelanggan salah satunya dilakukan oleh Kamil (2017) yang berjudul "Tingkat Kepuasan Pasien Terhadap Mutu Pelayanan Kesehatan di RSUDZA Banda Aceh". Dengan menggunakan metode servqual, penulis melakukan perhitungan nilai rata-rata dari Dimension by Dimension Score Analysis, Dimension by Dimension Gap Score analysis dan Index of Patient Satisfaction. Dari 93 orang jumlah sample responden yang populasinya berasal dari pasien rawat inap di rumah sakit pada 4-15 oktober 2010 didapatkan hasil penelitian dari setiap dimensi-dimensi diurutkan berdasarkan Gap Score Negative yaitu :Empati memiliki gap skor sebesar -0,9, Kehandalan sebesar -0,86, Ketanggapan dan Jaminan sama-sama gap skornya $-0,7$ serta tampilan fisik sebesar -0,6. Adapun skor Index of Patients Satisfaction sebesar 40,756\%. Sebagai saran untuk meningkatkan mutu pelayanan dari rumah sakit agar focus untuk memperbaiki semua dimensi dengan prioritas berurutan mulai dari Empati, Kehandalan, Ketanggapan, Jaminan dan Tampilan Fisik.

Penelitian lain yang menggunakan metode servqual untuk mengukur tingkat kepuasan pasien adalah Sitanggang (2018) dengan judul "Analysis of Satisfaction Level with Servqual method using Artificial Neural Networks". Dengan menggunakan metode servqual untuk menganalisis tingkat kepuasan mahasiswa akan pelayanan yang didapatkan di perguruan tinggi menunjukkan masih belum memenuhi harapan. Dari total 255 orang responden, sebanyak 182 orang $(82,67 \%)$ menunjukkan 'TidakPuas' dan hanya 39 orang $(17,33$ \%) yang merasa 'Puas'. Ini merupakan gambaran dari pelayanan yang diberikan pada periode semester ganjil tahun ajaran 2017/2018. Untuk meningkatkan kualitas pelayanan pada periode berikutnya, semua atribut dari kuesioner diurutkan berdasarkan nilai gap dan diprioritaskan yang 3 terendah untuk diperbaiki kinerjanya.

Service Quality (Servqual) dibangun berdasarkan perbandingan antara kenyataan dari pelayanan yang diterima oleh pelanggan (Perceived Service) dengan harapan dari layanan yang sesungguhnya mereka dapatkan (Expected Service) (Octy, 2014).

Dalam melakukan analisis metode servqual, ada pun langkah-langkahnya sebagai berikut (Okty, 2014): 
a. Mencari skor kenyataan dari setiap variabel Xi dan skor harapan dari setiap variabel Yi.

b. Menjumlahkan skor harapan (Yi) dan kenyataan (Xi), dari setiap variabel seluruh responden, kemudian dihitung rata-ratanya $\overline{(Y)} \operatorname{dan} \overline{(\mathrm{X})}$.

$\overline{\mathrm{X}}=\frac{\sum X i}{\mathrm{n}}$

$\overline{\mathrm{Y}}=\frac{\sum Y i}{\mathrm{n}}$

Dimana :

$\overline{\mathrm{X}}=$ Skor rata-rata tingkat kenyataan

$\overline{\mathrm{Y}}=$ Skor rata-rata tingkat harapan

$\mathrm{n}=$ Jumlah responden

c. Menghitung gap (kesenjangan) antara skor rata-rata kenyataan dengan skor rata-rata harapan.

$$
\mathrm{NSi}=\overline{(\mathrm{Xi})}-\overline{(\mathrm{Yi})}
$$

Dimana :

$\mathrm{NSi}=$ Skor rata-rata gap variabel ke-i

d. Menghitung rata-rata gap dari setiap variabel

$\overline{\mathrm{NSi}}=\frac{\sum_{\text {NSi }}}{\text { Ai }}$

Dimana :

$\overline{\mathrm{NSi}}=$ Nilai rata-rata gap pervariable ke-i

$\mathrm{Ai}=$ banyaknya atribut tiap variable ke-i

e. Kesimpulan hasil perhitungan skor kepuasan tiap dimensi dengan ketentuan :

- Skor servqual negatif $(<0)$ menunjukkan adanya kesenjangan antara kenyataan dengan harapan pelanggan, dikatakan "Tidak Puas".

- Skor servqual lebih besar atau sama dengan nol $(>=0)$, menunjukkan kenyataan telah sesuai atau melebihi harapan pelanggan, dikatakan "Puas".

\section{METODE}

Penelitian yang ini bersifat deskriptif, dilakukan untuk memberikan gambaran yang lebih rinci mengenai evaluasi kualitas pelayanan dan kepuasan. Penelitian dilakukan di Rumah Sakit Grandmed pada bulan Maret 2020 dengan sample penelitian berjumlah 98 orang dari total pasien rawat inap sebulan sebelum pengukuran ini dilakukan yang berjumlah 129 orang. Perhitungan jumlah sampel didapatkan berdasarkan rumus Slovin (Wirdha, 2015).

Dalam pengumpulan data, teknik yang digunakan adalah non-probability sampling dengan jenis purposive random sampling dan purposive random sampling. Dengan Purposive random sampling, peneliti memiliki anggapan bahwa responden memberikan data secara pasti, lengkap dan akurat. Sedangkan purposive random sampling digunakan dalam menetapkan sampel yang semua anggotanya memiliki peluang yang sama dan tidak terikat oleh apapun.

Sebagai alat untuk mengumpulkan data adalah kuesioner dengan 32 atribut pernyataan dan dibagikan kepada responden dalam bentuk skala lima tingkat (linkert) (Tabel 1).

Tabel 1. Skala lima tingkat (likert)

\begin{tabular}{|c|c|c|c|c|}
\hline \multirow{2}{*}{ No. } & \multicolumn{2}{|l|}{ Harapan } & \multicolumn{2}{|c|}{ kenyataan } \\
\hline & Keterangan & Skor & Keterangan & Skor \\
\hline 1. & $\begin{array}{l}\text { Sangat Tidak } \\
\text { Penting (STP) }\end{array}$ & 1 & $\begin{array}{l}\text { Sangat Tidak } \\
\text { Setuju (STS) }\end{array}$ & 1 \\
\hline 2. & $\begin{array}{ll}\text { Tidak } & \text { Penting } \\
\text { (TP) } & \end{array}$ & 2 & $\begin{array}{l}\text { Tidak Setuju } \\
\text { (TS) }\end{array}$ & 2 \\
\hline 3. & $\begin{array}{l}\text { Cukup Penting } \\
\text { (CP) }\end{array}$ & 3 & $\begin{array}{l}\text { Cukup Setuju } \\
\text { (CS) }\end{array}$ & 3 \\
\hline 4. & Penting (P) & 4 & Setuju (S) & 4 \\
\hline 5. & $\begin{array}{l}\text { Sangat Penting } \\
\text { (SP) }\end{array}$ & 5 & $\begin{array}{l}\text { Sangat Setuju } \\
\text { (SS) }\end{array}$ & 5 \\
\hline
\end{tabular}

Adapun jumlah atribut-atribut pernyataan tersebut berdasarkan variable penelitian dikelompokkan menjadi : Bukti Fisik memiliki 8 atribut pernyataan, Kehandalan memiliki 7 atribut pernyataan, Daya Tanggap 
memiliki 6 atribut pernyataan, Jaminan memiliki 6 atribut pernyataan dan Empati sebanyak 5 atribut pernyataan (Sunarto, 2010).

\section{HASIL}

Hasil penelitian ini menunjukkan karakteristik dari responden yang dibagi menjadi beberapa kategori. Dalam tabel 2 memperlihatkan bahwa terdapat persentasi sebanyak $83,67 \%$ atau berjumlah 82 orang berjenis kelamin wanita dan yang berjenis kelamin pria dengan persentasi $16,33 \%$ atau sebanyak 16 orang.

Tabel 2. Jenis Kelamin Responden

\begin{tabular}{|c|l|c|r|}
\hline No. & Jenis Kelamin & Jumlah & Persentase \\
\hline 1 & Pria & 16 & 16,33 \\
\hline 2 & Wanita & 82 & 83,67 \\
\hline \multicolumn{2}{|c|}{ Total } & $\mathbf{9 8}$ & $\mathbf{1 0 0 , 0 0}$ \\
\hline
\end{tabular}

Berdasarkan kategori usia (tabel 3), responden terbanyak berada pada rentang usia 17 s.d. 24 tahun dengan persetasi $50,00 \%$ yang berjumlah 49 orang, rentang terbanyak berikutnya ada di 35 s.d. 49 tahun dengan persentasi $18,37 \%$ yang berjumlah 18 orang, lebih kecil dari 17 tahun dengan persentasi $13,27 \%$ yang berjumlah 13 orang, di rentang 25 s.d. 34 tahun dengan persentasi $12,24 \%$ yang berjumlah 12 orang dan yang umurnya 65 tahun atau lebih memiliki persentasi $6,12 \%$ yang berjumlah 6 orang.

Tabel 3. Rentang Usia Responden

\begin{tabular}{|c|l|c|r|}
\hline No. & \multicolumn{1}{|c|}{ Usia } & Jumlah & Persentase \\
\hline 1 & $\begin{array}{l}\text { Lebih kecil } \\
\text { dari } 17 \text { tahun }\end{array}$ & 13 & 13,27 \\
\hline 2 & $\begin{array}{l}17 \text { s.d. } 24 \\
\text { tahun }\end{array}$ & 49 & 50,00 \\
\hline 3 & $\begin{array}{l}25 \text { s.d. } 34 \\
\text { tahun }\end{array}$ & 12 & 12,24 \\
\hline 4 & $\begin{array}{l}35 \text { s.d. } 49 \\
\text { tahun }\end{array}$ & 18 & 18,37 \\
\hline 5 & $\begin{array}{l}\text { lebih atau } \\
\text { sama dengan } \\
65 \text { tahun }\end{array}$ & 6 & 6,12 \\
\hline
\end{tabular}

Dari tabel 4 didapatkan persentasipersentasi responden berdasarkan kategori lama perawatan. Responden paling banyak berdasarkan lama perawatan adalah dibawah 3 hari sebanyak 43 orang dengan persetasi $43,88 \%$, selanjutnya yang lama perawatan 3 s.d. 6 hari sebanyak 36 orang dengan persentasi 36,73\%, kemudian yang lama perawatannya telah melewati 15 hari terdapat sebanyak 15 orang dengan persentasi 15,31 dan lama perawatan 7 s.d. 15 hari sebanyak 4 orang dengan persentasi 4,08.

Tabel 4. Lama Perawatan Responden

\begin{tabular}{|c|l|c|r|}
\hline No. & Lama di rawat & Jumlah & Persentase \\
\hline 1 & $\begin{array}{l}\text { Belum sampai } \\
\text { 3 hari }\end{array}$ & 43 & 43,88 \\
\hline 2 & 3 s.d. 6 hari & 36 & 36,73 \\
\hline 3 & 7 s.d. 15 hari & 4 & 4,08 \\
\hline 4 & $\begin{array}{l}\text { sudah lebih } \\
\text { dari 15 hari }\end{array}$ & 15 & 15,31 \\
\hline \multicolumn{2}{|l|}{ Total } & $\mathbf{2 2 5}$ & $\mathbf{1 0 0 , 0 0}$ \\
\hline
\end{tabular}

Dari hasil pengolahan data kuesioner yang dikumpulkan dari responden menunjukkan bahwa pengukuran tingkat kepusan pasien terhadap mutu pelayanan pada periode ini secara keseluruhan telah sesuai dengan harapan dengan gap skor tingkat kepuasan sebesar 0,10 atau bernilai positif seperti tampak pada tabel 5 . Pernyataan tersebut dapat dibuktikan dengan perbandingan persentasi tingkat kepuasan pasien yang "Puas" sebesar $53,06 \%$ atau berjumlah 52 responden dengan yang "Tidak Puas" sebesar $46,94 \%$ atau sebanyak 46 responden dari total 98 orang yang dijadikan sampel penelitian.

Secara keseluruhan variabelvariabel menunjukkan gap skor tingkat kepuasan yang berasal dari selisih antara kenyataan dengan harapan dari keseluruhan skor kelima dimensidimensi servqual yang terdapat pada tabel 5. Gap skor yang menunjukkan 
kinerja "Puas" yang tertinggi ada pada dimensi "Jaminan" dengan gap skor sebesar 0,22, selanjutnya "Bukti Fisik" dengan gap skor 0,16, "Empati" sebesar 0,12 dan "Kehandalan" sebesar 0,08. Namun terdapat 1 dimensi yang menunjukkan kinerja "Tidak Puas" yaitu "Daya Tanggap" yang bernilai negative dengan gap skor $-0,08$.

Tabel 5. Gap skor atribut-atribut pernyataan

\begin{tabular}{|c|c|c|c|c|c|}
\hline \multirow{2}{*}{$\begin{array}{l}\text { Atri } \\
\text { but } \\
\text { No. }\end{array}$} & \multirow[b]{2}{*}{ Pernyataan } & \multicolumn{2}{|c|}{$\begin{array}{c}\text { Rata-rata } \\
\text { Nilai }\end{array}$} & \multirow{2}{*}{$\begin{array}{c}\text { Gap } \\
\text { Scor } \\
\text { e }\end{array}$} & \multirow{2}{*}{$\begin{array}{c}\text { Rata } \\
- \\
\text { rata }\end{array}$} \\
\hline & & $\begin{array}{l}\text { Ken } \\
\text { yata } \\
\text { an }\end{array}$ & $\begin{array}{c}\text { Hara } \\
\text { pan }\end{array}$ & & \\
\hline \multicolumn{6}{|c|}{ Bukti Fisik } \\
\hline 1 & $\begin{array}{l}\text { Ruang Pelayanan } \\
\text { yang dimiliki } \\
\text { mudah untuk } \\
\text { semua orang }\end{array}$ & 4,14 & 4,43 & $0,-$ & \multirow{8}{*}{0,16} \\
\hline 2 & $\begin{array}{l}\text { Alat-alat pelayanan } \\
\text { yang dimiliki }\end{array}$ & 4,18 & 3,51 & 0,67 & \\
\hline 3 & $\begin{array}{l}\text { Ruang Tunggu } \\
\text { pasien yang }\end{array}$ & 4,15 & 3,47 & 0,68 & \\
\hline 4 & $\begin{array}{l}\text { Ruang Mandi, Cuci, } \\
\text { Kakus untuk semua } \\
\text { pasien }\end{array}$ & 4,15 & 3,92 & 0,23 & \\
\hline 5 & $\begin{array}{l}\text { Tempat parkir yang } \\
\text { ada }\end{array}$ & 4,22 & 4,10 & 0,12 & \\
\hline 6 & $\begin{array}{l}\text { Sarana/Media } \\
\text { komunikasi yang } \\
\text { disediakan untuk } \\
\text { semua pasien }\end{array}$ & 4,16 & 3,82 & 0,35 & \\
\hline 7 & $\begin{array}{l}\text { Transparansi } \\
\text { (ketersediaan } \\
\text { kejelasan alur } \\
\text { pelayanan, tarif, } \\
\text { jadwal pelayanan, } \\
\text { jadwal petugas) }\end{array}$ & 4,19 & 4,51 & $\overline{-}, 32$ & \\
\hline 8 & $\begin{array}{l}\text { Ketersediaan obat } \\
\text { untuk pasien }\end{array}$ & 4,24 & 4,46 & $\overline{-}, 21$ & \\
\hline \multicolumn{6}{|c|}{ Kehandalan } \\
\hline 9 & $\begin{array}{l}\text { Pemberian } \\
\text { pelayanan yang } \\
\text { diberikan kepada } \\
\text { pasien }\end{array}$ & 4,27 & 4,08 & 0,18 & \multirow{7}{*}{0,08} \\
\hline 10 & $\begin{array}{l}\text { Kesesuaian } \\
\text { diagnosis } \\
\text { pemberian } \\
\text { pelayanan }\end{array}$ & 4,18 & 4,04 & 0,14 & \\
\hline 11 & $\begin{array}{l}\text { Ketepatan waktu } \\
\text { pemberian } \\
\text { pelayanan sesuai } \\
\text { dengan yang }\end{array}$ & 4,20 & 3,92 & 0,29 & \\
\hline 12 & $\begin{array}{l}\text { Pengobatan yang } \\
\text { telah diberikan }\end{array}$ & 4,23 & 4,58 & $\overline{0}, \overline{35}$ & \\
\hline 13 & $\begin{array}{l}\text { Dokter } \\
\text { menjelaskan resiko } \\
\text { atas tindakan }\end{array}$ & 4,26 & 4,47 & $\overline{0}, 21$ & \\
\hline 14 & $\begin{array}{l}\text { Pemenuhan hak- } \\
\text { hak pasien oleh } \\
\text { petugas paramedis } \\
\text { (bidan/perawat) }\end{array}$ & 4,27 & 3,93 & 0,34 & \\
\hline 15 & $\begin{array}{l}\text { Pemenuhan hak- } \\
\text { hak pasien oleh }\end{array}$ & 4,19 & 4,02 & 0,17 & \\
\hline \multicolumn{6}{|c|}{ Daya Tanggap } \\
\hline 16 & $\begin{array}{l}\text { Jika ada } \\
\text { pelanggan, para } \\
\text { staf segera ingin } \\
\text { membantu tanpa }\end{array}$ & 4,15 & 4,10 & 0,05 & $\overline{-}$ \\
\hline
\end{tabular}

\begin{tabular}{|c|c|c|c|c|c|}
\hline 17 & $\begin{array}{l}\text { Pemberian } \\
\text { pelayanannya } \\
\text { (tindakan) sesuai } \\
\text { dengan keluhan }\end{array}$ & 4,23 & 4,13 & 0,10 & \\
\hline 18 & $\begin{array}{l}\text { Keterampilan } \\
\text { dalam menangani } \\
\text { penyakit yang telah } \\
\text { ditunjukkan oleh } \\
\text { Dokter }\end{array}$ & 4,22 & 4,47 & 0,24 & \\
\hline 19 & $\begin{array}{l}\text { Tanggapan Dokter } \\
\text { ketika menjawab } \\
\text { pertanyaan yang } \\
\text { diajukan oleh } \\
\text { pasien } \\
\end{array}$ & 4,22 & 4,49 & $0,-\overline{27}$ & \\
\hline 20 & $\begin{array}{l}\text { Tanggapan } \\
\text { perawat/bidan } \\
\text { ketika menjawab } \\
\text { pertanyaan yang } \\
\text { diajukan pasien }\end{array}$ & 4,23 & 3,97 & 0,27 & \\
\hline 21 & $\begin{array}{l}\text { Keluhan pasien } \\
\text { dapat }\end{array}$ & 4,16 & 4,56 & $0, \overline{40}$ & \\
\hline \multicolumn{6}{|c|}{ Jaminan } \\
\hline 22 & $\begin{array}{l}\text { Dokter memiliki } \\
\text { pengetahuan yang } \\
\text { luas tentang } \\
\text { penyakit yang } \\
\end{array}$ & 4,20 & 3,94 & 0,27 & \multirow{6}{*}{0,22} \\
\hline 23 & $\begin{array}{l}\text { Pengetahuan yang } \\
\text { dimiliki oleh } \\
\text { perawat atau bidan } \\
\text { tentang penyakit }\end{array}$ & 4,20 & 4,19 & 0,01 & \\
\hline 24 & $\begin{array}{l}\text { Sopan santun yang } \\
\text { telah ditunjukkan } \\
\text { kepada pasien }\end{array}$ & 4,31 & 4,47 & $\overline{-}$ & \\
\hline 25 & $\begin{array}{l}\text { Perhatian } \\
\text { perawat/bidan } \\
\text { yang telah } \\
\text { ditunjukkan kepada }\end{array}$ & 4,23 & 3,94 & 0,30 & \\
\hline 26 & $\begin{array}{l}\text { Pegawai-pegawai } \\
\text { Rumah sakit } \\
\text { menyenangkan }\end{array}$ & 4,20 & 4,02 & 0,18 & \\
\hline 27 & $\begin{array}{l}\text { Petugas nonmedis } \\
\text { (perawat dan } \\
\text { bidan) } \\
\text { menyenangkan } \\
\end{array}$ & 4,21 & 3,50 & 0,71 & \\
\hline \multicolumn{6}{|c|}{ Empati } \\
\hline 28 & $\begin{array}{l}\text { Pemanggilan di } \\
\text { tempat } \\
\text { pendaftaran yang } \\
\text { dilakukan petugas } \\
\text { mudah diterima } \\
\text { semua pasien } \\
\end{array}$ & 4,21 & 4,05 & 0,16 & \multirow{5}{*}{0,12} \\
\hline 29 & $\begin{array}{l}\text { Nasehat yang } \\
\text { diberikan dokter } \\
\text { ketika memberikan } \\
\text { pelayanan }\end{array}$ & 4,26 & 4,47 & 0,21 & \\
\hline 30 & $\begin{array}{l}\text { Interaksi dengan } \\
\text { petugas (non- }\end{array}$ & 4,18 & 3,98 & 0,20 & \\
\hline 31 & $\begin{array}{l}\text { Interaksi dengan } \\
\text { Dokter }\end{array}$ & 4,22 & 4,04 & 0,18 & \\
\hline 32 & $\begin{array}{l}\text { Waktu konsultasi } \\
\text { dengan Dokter }\end{array}$ & 4,18 & 3,94 & 0,24 & \\
\hline \multicolumn{5}{|c|}{ RATA-RATA TINGKAT KEPUASAN } & 0,10 \\
\hline
\end{tabular}

Dari pengolahan data kuesioner berdasarkan kinerja dari 32 item atribut-atribut pernyataan (tabel 6.), kinerja dengan gap skor yang paling tinggi ada pada atribut pernyataan No. 27 "Petugas non medis (perawat dan bidan) menyenangkan" sebesar 0,71. Sedangkan kinerja dengan gap skor paling rendah berada pada atribut pernyataan dengan No. 21 "Keluhan 
pasien dapat ditindaklanjuti" sebesar 0,40 .

Tabel 6. Urutan Peringkat Kinerja atribut-atribut Pernyataan

\begin{tabular}{|c|c|c|c|}
\hline Dimensi & $\begin{array}{c}\text { Atribut } \\
\text { No. }\end{array}$ & $\begin{array}{l}\text { Gap } \\
\text { Skor }\end{array}$ & Peringkat \\
\hline \multirow{8}{*}{ Bukti Fisik } & 1 & $-0,29$ & 29 \\
\hline & 2 & 0,67 & 3 \\
\hline & 3 & 0,68 & 2 \\
\hline & 4 & 0,23 & 11 \\
\hline & 5 & 0,12 & 19 \\
\hline & 6 & 0,35 & 4 \\
\hline & 7 & $-0,32$ & 30 \\
\hline & 8 & $-0,21$ & 24 \\
\hline \multirow{8}{*}{ Kehandalan } & 9 & 0,18 & 13 \\
\hline & 10 & 0,14 & 18 \\
\hline & 11 & 0,29 & 7 \\
\hline & 12 & $-0,35$ & 31 \\
\hline & 13 & $-0,21$ & 25 \\
\hline & 14 & 0,34 & 5 \\
\hline & 15 & 0,17 & 16 \\
\hline & 16 & 0,05 & 21 \\
\hline \multirow{5}{*}{ Daya Tanggap } & 17 & 0,10 & 20 \\
\hline & 18 & $-0,24$ & 27 \\
\hline & 19 & $-0,27$ & 28 \\
\hline & 20 & 0,27 & 8 \\
\hline & 21 & $-0,40$ & 32 \\
\hline \multirow{6}{*}{ Jaminan } & 22 & 0,27 & 9 \\
\hline & 23 & 0,01 & 22 \\
\hline & 24 & $-0,16$ & 23 \\
\hline & 25 & 0,30 & 6 \\
\hline & 26 & 0,18 & 14 \\
\hline & 27 & 0,71 & 1 \\
\hline \multirow{5}{*}{ Empati } & 28 & 0,16 & 17 \\
\hline & 29 & $-0,21$ & 26 \\
\hline & 30 & 0,20 & 12 \\
\hline & 31 & 0,18 & 15 \\
\hline & 32 & 0,24 & 10 \\
\hline
\end{tabular}

\section{PEMBAHASAN}

Berdasarkan analisis gap skor dari semua dimensi yang terdapat pada tabel 5 dapat disimpulkan bahwa terdapat 4 dimensi dengan gap skor positif yaitu dimensi Jaminan, Bukti Fisik, Empati dan Kehandalan. Untuk menyempurnakan tingkat kepuasan pasien secara keseluruhan agar meningkatkan atribut-atribut pernyataan pada dimensi Daya Tanggap yang memiliki gap skor negatif.

Berdasarkan tabel 6 yang merupakan hasil dari 32 atribut-atribut pernyataan menunjukkan bahwa terdapat beberapa atribut pernyataan yang harus ditingkatkan kinerjanya karena gap skornya bernilai negatif.

\section{Dimensi Bukti Fisik}

Pada dimensi ini terdapat 3 atribut pernyataan dengan gap skor negatif. Adapun atribut pernyataan yang perlu ditingkatkan kinerjanya secara berurutan sebagai berikut : atribut pernyataan nomor 7 dengan gap skor sebesar-0,32, atribut nomor 1 dengan gap skor sebesar -0,29 dan atribut pernyataan nomor 8 dengan gap skor 0,21 .

\section{Dimensi Kehandalan}

Pada dimensi ini terdapat 2 atribut pernyataan dengan gap skor negatif. Adapun atribut pernyataan yang perlu ditingkatkan kinerjanya secara berurutan sebagai berikut : atribut pernyataan nomor 12 dengan gap skor sebesar -0,35 dan atribut pernyataan nomor 13 dengan gap skor -0,21.

\section{Dimensi Daya Tanggap}

Pada dimensi ini terdapat 3 atribut pernyataan dengan gap skor negatif. Adapun atribut pernyataan yang perlu ditingkatkan kinerjanya secara berurutan sebagai berikut : atribut pernyataan nomor 21 dengan gap skor sebesar -0,40, atribut pernyataan nomor 19 dengan gap skor sebesar 0,27 dan atribut pernyataan nomor 18 dengan gap skor -0,24.

\section{Dimensi Jaminan}

Pada dimensi ini terdapat 1 atribut pernyataan dengan gap skor negatif. 
Adapun atribut pernyataan yang perlu ditingkatkan kinerjanya yaitu atribut pernyataan nomor 24 dengan gap skor sebesar $-0,16$.

\section{Dimensi Empati}

Pada dimensi ini terdapat 1 atribut pernyataan dengan gap skor negatif. Adapun atribut pernyataan yang perlu ditingkatkan kinerjanya yaitu atribut pernyataan nomor 29 dengan gap skor sebesar $-0,21$.

\section{KESIMPULAN}

Pengukuran tingkat kepuasan pasien akan mutu pelayanan rumah sakit pada periode periode maret 2020 secara keseluruhan pasien dinyatakan "Puas", namun secara dimensi masih terdapat gap skor yang masih bernilai negatif atau "Tidak Puas" pada dimensi Daya Tanggap.

Dan untuk pengukuran tingkat kepuasan pasien pada periode berikutnya agar memperbaiki kinerja pada atribut-atribut pernyataan pada nomor1, 7, 8, 12,13, 19, 21, 24, dan 29 (bersarkan gap skor negatif pada tabel 6).

\section{DAFTAR PUSTAKA}

Lissa Rosdiana Noer. 2016. Analisis Pengingkatan Kualitas Pelayanan Mahasiswa Magister Manajemen Teknologi ITS Surabaya dengan Metode Servqual dan Importance Performance Analysis (IPA). Journal of Research and Technologies, Vol. 2, No. 1, Juni 2016, hal. 36-43.

Kamil, H. 2017. Tingkat Kepuasan Pasien Terhadap Mutu Pelayanan Kesehatan di RSUDZA Banda Aceh. Idea Nursing Journal. Vol. III, No. 1, Maret 2017, hal 1-10.

Erwin Daniel Sitanggang et al. $2019 \mathrm{~J}$. Phys.: Conf. Ser. 1235012061.

Octy P. Sianipar. 2014. Analisis Pengaruh Kualitas pelayanan Terhadap Kepuasan Konsumen dengan Metode Servqual (Service Quality) Studi Kasus di Nest
Caffee, Kota Jombang. Skripsi Universitas Brawijaya.

Wirdha Purnomo \& Dyah Riandadari. 2015. Analisa Kepuasan Pelanggan terhadap Bengkel dengan Metode IPA (Importance-Performance Analysis) di PT. Arina Parama Jaya Grasik. JTM, Vol. 03, No. 03, 2015, hal. 54-63.

Sunarto. 2010. Analisis Tingkat Kepuasan dan Harapan Pasien terhadap Pelayanan Puskesmas dan Rumah Sakit Daerah di Propinsi DIY. Jurnal Kesehatan Masyarakat, Vol. 05, No. 01, 2010, hal. 28-35. 